\title{
Does anything we do matter forever?
}

\author{
T. J. MAWSON \\ St Peter's College, Oxford University, Oxford, OX1 2DL \\ Email: tim.mawson@philosophy.ox.ac.uk
}

\begin{abstract}
In this paper, I consider the question of whether or not any action we perform matters forever. I distinguish two senses of mattering, which I call 'relative' and 'non-relative' mattering; and I argue that the answers one should give to the questions of whether or not anything we do matters forever in these senses depend on one's worldview. I thus consider the questions from an atheistic naturalistic worldview and from two variants of the theistic worldview. Finally, I argue that on any plausible variants of these worldviews, we either are already in or will end up in a state where nothing we do matters forever in the non-relative sense. And I consider whether or not it matters now that this is where we are or will end up. I conclude that on atheistic naturalism and on one variant of theism, it doesn't non-relatively matter now and on another variant of theism it does non-relatively matter now. I conclude that, on both variants of theism, it relatively and non-relatively matters at the time it obtains.
\end{abstract}

\section{Introduction}

In many of our actions, we aim at leaving the world a better place than we found it. Perhaps especially if we take ourselves to be near the end of our lives, we have hopes of doing something before we go that will be significant after we're dead, ideally perhaps long after we're dead. Certainly the intention to leave such a legacy has been behind some of the most important creations of philosophers, artists, scientists, and figures in public life. But we also, I suggest, find in our more humdrum lives a desire for at least some of our actions to have lasting significance; we want at least some of what we do to matter and to continue mattering. Ideally - if perhaps, we suppose, unrealistically - we'd like at least some of what we do to continue mattering forever, for us to be able to make a positive difference to the value of reality that time will never erase. If we are drawn to worldviews which seem to rule out as a possibility the realisation of this hope, then we may consequently incline to take that aspect of these worldviews as a source for a certain sort of regret, albeit that the very impossibility of the hope's being realised may in itself mitigate the regret that it will not be realised; if it's no use crying over spilt milk, it's perhaps no use crying over milk which of metaphysical necessity we could never have got. Conversely, if we are drawn to worldviews which seem to promise us that the hope will be realised, we may consequently take that aspect of these worldviews as a source of comfort. My aim in this paper is to show that the desire that some of what we do matter forever may very well be unresponsive to genuine desirability; it may very well be better for us if we matter forever as individuals in a way that precludes anything we do mattering forever in at least one sense.

A significant sub-conclusion in this paper is that, on every plausible worldview, each of us has reached or will reach a point after which none of our actions matter forever in one significant sense of mattering (that which I shall call non-relative mattering); on the most plausible variants of atheistic naturalism and theistic universalism, each of us has in fact already reached that point. My conclusion is that the fact that we are already in a state or will get to a state where nothing we do matters (non-relatively) is in itself a fact that matters (nonrelatively) for us now on one variant of theism (the non-universalistic one), but not on atheistic naturalism or the other variant of theism (the universalistic one). On the universalistic variant of theism, it does non-relatively matter, but it does so not in the manner 
gestured to in the previous paragraph, but in a good way; it'd actually be worse for us if that aspiration of ours to make an everlasting difference to the value of reality were to be forever honoured by reality. Or so I shall suggest.

Section I of this paper takes some time to distinguish what it is I am taking mattering forever to be and argues for the necessity of persons for mattering. The second section of the paper applies this so as to bring clarity to the title question and enable us to see how, on the three views of our ultimate destiny which it considers, that question - or rather questions - should be answered. I say 'questions' as by then two different senses of mattering will have been distinguished from one another. The final section of the paper turns to whether or not the facts of mattering as they have by then been laid out are themselves ones that matter in any sense for us now and whether or not they are ones that will matter in any sense for us in the future.

\section{I - What would it be for an action of ours to matter forever?}

What is it for some action of ours ${ }^{1}$ to matter, or - as I shall sometimes put it - to have importance or significance ${ }^{2}$ And what would it be for an action of ours to have it forever? I shall first outline how it is that I shall understand 'forever'.

There may well be a sense in which some of what we do matters 'from the point of view of eternity'; an atemporal being may look down on some action of ours and eternally care about it, find it important. Perhaps some of what we do inside time leaves a significant mark in some way in a realm beyond time and, through doing so, matters there. Be that as it may, in the question that I've set myself, I intend the word 'forever' to facilitate me in putting such issues to one side, as I take it that 'forever' is a temporal and forward-looking notion. In asking if anything we do matters forever then, I am asking whether any action of ours is such as to have the property (or at least one of the properties, of which more in a moment) that we pick out by 'mattering' such that there is no time after that at which we perform the action at which it fails to have that property (or rather at least one of these properties). For an action to matter forever is for it to matter for ever more. If that definition of 'forever' strikes the reader as stipulative, so be it; it usefully narrows the focus of my subsequent inquiry.

If that's what it would be for an action of ours to matter forever, what then is it for any action of ours to matter at all? This will take a bit more time.

Williams considers the fact that someone - he dubs him 'Henry' - might be such that his completing his stamp collection with a particular stamp is very important to him. ${ }^{3}$ Although Williams doesn't draw this out, it seems to me that this sort of importance (or mattering) to someone of an action is their caring about it. There seems a contradiction in admitting the psychological fact that Henry cares about purchasing a particular stamp whilst also asserting that it doesn't matter to Henry at all whether or not he purchases this stamp. Similarly, there seems a contradiction in saying that it isn't at all important to or significant to Henry, but he nevertheless cares about it. In ordinary language (but not in the sense I am introducing), importance of this sort is plausibly a threshold concept; one needs to care about something quite a bit for it to be called important to one. On the construal I am advancing, if one cares about a given action at all (however minimally), then that is sufficient for it to matter/be important/significant to one (at least minimally) and I would agree that this usage is somewhat idiosyncratic. Still, I think it carves reality at the joints rather better than ordinary language and so I shall persist with it. ${ }^{4}$ 
This then is mattering/being important/having significance-to-someone. And given its 'tosomeone' nature, thus, it seems to me, Williams is sensible to call this, as he does, 'relative importance' - it's relative to a person (or persons) and their cares. Williams focuses on the notion of 'relative importance', but it will be recalled that I am suggesting that the notions of 'relative mattering' and 'relative significance' may be used to mark out the same conceptual territory. And I am now additionally suggesting that - traveling in the other direction, as it were - the notion of 'caring' goes over the same ground: an action's having relative mattering (relative importance or relative significance) to a person is that person's caring about that action. ${ }^{5}$ This is obviously a gradable property. Henry's completing his stamp collection relative-matters to him and so - we may speculate - does his putting the rubbish bins out, but the first may well relative-matter to him much more than the second.

As well as the relative sense of mattering, there's another sense of mattering - a non-relative one. This is the sense in which we can all see that whether or not Henry completes his stamp collection doesn't in fact - however much he might happen to care about it - matter much (if at all). It matters to him - relative-mattering. It doesn't matter tout court (or matter much) non-relative-mattering. ${ }^{6}$ It might matter far more in this non-relative sense that a direct-debit that Henry set up from his bank account several years ago and which now regularly sends money to a worthy charity continues to operate, even though to Henry himself - his having all but forgotten that he did set it up - it doesn't matter much (if at all) that he continues regularly to give to this charity in this way. I am then taking caring as an occurrent mental state - it doesn't now occur to Henry to care about this; ipso facto, he doesn't now care about this; ipso facto, it doesn't now matter to him. ${ }^{7}$ Non-relative mattering too is a gradable property. Amongst the things that Henry does that have this sort of non-relative mattering, some will no doubt non-relatively matter more than others. Perhaps that Henry continue to give regularly through this direct debit to the worthy charity non-relatively matters more than that he continue to send his nephew timely birthday cards, even though the latter does nonrelatively matter to at least some extent. This sort of non-relative mattering of an action one might call its making a difference to 'objective value'. That objective value exists is not uncontroversial, but I assume its existence in what follows.

In virtue of relative mattering and non-relative mattering being both gradable, the terminology of relative and non-relative isn't perhaps ideal. It isn't perhaps ideal as, within each sort of mattering, we might find ourselves wanting to make the sort of grading judgments I've just made and thus wanting to talk about different actions mattering relative to one another interior to each of the domains of relative mattering and non-relative mattering. For example, we might wish to claim that Henry's charitable giving relatively non-relatively matters more than does his sending birthday cards to his nephew. Also, the terminology is not ideal due to the fact that I shall in due course look favourably on the thesis that all nonrelative mattering is nevertheless mattering for people (or sentient life more generally), which could then be said to 'relativize' even this objective, or - as I am putting it - non-relative mattering, relativize it to people (or sentient life more broadly). Still, those infelicities having been noted, the Williams-inspired terminology of relative and non-relative mattering seems workable in carving two types of mattering off from one another and I shall stick with it. ${ }^{8}$ (I should say that Williams doesn't make all the points that I have already made with his terminology, nor perhaps would he agree with all of them. In particular, it seems that Williams in the end thought that the sort of non-relative mattering that I am suggesting exists doesn't exist. I have in mind here primarily his posthumously published essay, 'The Human Prejudice'. ${ }^{9}$ ) 
It is worth pointing out that Henry himself need not suppose that his finishing his stamp collection has great non-relative mattering. Of course people can become rather overinvolved in their hobbies; Henry might suppose that it matters enormously in some nonrelative sense that he completes his collection; he might think that he somehow has an overwhelming categorical obligation to the philatelic world to do this; but he needn't get so confused. Henry himself might soberly admit that whilst it matters a lot to him that he purchase this last missing stamp, it matters a lot less in the non-relative sense that he do so than that he continue his regular donation to the worthy charity that he supports and has just remembered he supports. He can do all this even if he frankly admits that he cares a lot less about his charitable giving than he does about buying this stamp.

So, an action's mattering (having importance or significance) in the relative sense requires that there be a person to whom it matters (is important and significant); its mattering in this sense to that person just is that person caring about it. If there will be a time after which no persons exist, then there can be no relative-mattering after that time. Therefore, those who hold to worldviews which predict an end to persons cannot consistently hold that anything we do relatively-matters forever. Relative-mattering can last only as long as caring, and caring can last only as long as persons (or certain types of sentient life more generally, though I am largely ignoring this technicality). By contrast, an action's mattering in the non-relative sense does not require that there be someone to whom it matters. Or, if it does, then the fact that it does is due to some deep fact about the metaphysics of value - e.g. that the non-relative sort of mattering, importance, and significance, is grounded in the cares of God or some such being. In any case, it isn't a contradiction to say that something might have non-relative mattering, importance, or significance and yet there not be any person who cares about it, any person to whom it matters. It isn't then a contradiction to say that this sort of mattering might continue on after the last person has ceased to exist.

Consider now the following thought experiment, which will make plain the need for another distinction.

Suppose that, even now, an alien is orbiting the Earth in his spaceship and is about to decide whether or not to try out his new planet-destroying weapon on us. He may fly on to another solar system and try it out on an uninhabited planet there instead. It doesn't matter much to him either way. If he tries it out on us, then we will all die instantly. If he tries it out on the other planet, no sentient life will be adversely affected at all. We, who not only do not suspect that such an alien exists, but also cannot seriously entertain the possibility that he does, thus do not care about what he does (we can't bring ourselves to believe he even exists). So, given that caring just is relative mattering, whether or not this alien destroys us cannot matter to us; it is not important or significant to us whether or not he destroys Earth. ${ }^{10}$ But it nevertheless non-relatively matters what he does in this regard; it is nevertheless non-relatively important and significant. Or so I am assuming; and, whatever Williams may in the end say, I, in the end, don't think of the assumption as a prejudice or anyway as an error. Why then does it non-relatively matter where the alien tries out his new weapon? Why is it non-relatively important/significant whether or not the weapon is used to destroy Earth, rather than some uninhabited planet in another solar system? The answer, it seems to me, is that it is because Earth is where we are and we are objectively valuable (as indeed, I would say, is sentient life more generally); so actions which affect us can non-relatively matter - non-relative mattering being, it will be recalled, making a difference to objective value, which sort of value, it will be recalled, I am assuming exists. 
Our terminology might seem to rule out the possibility that what makes something nonrelatively important might be its effects on people, but that would be most implausible. This helps us see the need to make a distinction between something's mattering to someone and what I'm going to call something's mattering for someone. Whether or not the alien uses his weapon on us does not relatively-matter/is not relatively important to us; but it non-relatively matters/is important for us. This for-us importance/mattering then is an action affecting the value of 'our bits' of reality; something's being non-relatively important or significant, its non-relatively mattering, for a person, is his or her being affected in value terms by it.

Allow me now to turn to consider the plausibility of what one might call a person-affecting or, as I would prefer it, sentient-life-affecting - requirement on non-relative importance. I won't in future add the technicality that I'd extend the requirement to be a sentient-lifeaffecting one and I'll tend to call the view 'Welfarism'. Is it that when actions have nonrelative importance, they do so in all cases because they are important for someone, they affect someone's welfare (broadly construed)? Frankly, I don't know quite what to think here. But, fortunately for my argument, I don't need to know quite what to think to proceed.

This is because, firstly, it seems to me that any actions which do manage to get some value without that value being due to their affecting welfare don't manage to get any value that has non-relative importance. That is to say that whilst I might on balance incline to reject a welfare-affecting requirement on value per se, non-welfare-affecting values, should they exist at all, aren't - it seems to me - non-relatively important values; if they exist, they just don't non-relatively matter. Secondly, it seems to me that any of these (not non-relatively important values) that any of our actions manage to produce clearly don't last forever on any plausible worldview. Either way then, they are irrelevant to our question.

In support of the first point, consider two worlds, A and B, that are almost exactly alike and each of which is much like the actual world. In each, there is an Earth, with people like us on it. The only difference between the two is as follows. In world A, an object with a certain non-welfare-related value - perhaps a supremely beautiful crystal formation - exists on a planet beyond the light cone of any inhabited planet (e.g. its Earth). In world B, that crystal does not exist. Simply in order to remove any person for whom this could make a difference, let us finally stipulate that there is no God, god or other sort of superbeing, in either world. Is there any important difference between these two worlds? I tend to think not. ${ }^{11}$

In support of the second point, suppose that an artist creates an object with a certain nonwelfare-related value - a supremely beautiful sculpture, say - and locks it into some bombproof shelter. It is then forgotten about; it stays there with its non-welfare-related value for hundreds of years - long after it has ceased to matter to anyone that the artist produced it and indeed to matter for anyone that it's there; it outlasts in fact the demise of the human race. But still, it seems that there will come a time at which it will cease to exist; then whatever non-welfare-related value it had will, along with all its other properties, be lost. Its value of this sort can no more continue after it has been destroyed than can its shape.

So, to sum up where we've got to so far: the non-relative importance/significance of an action - its objective value - is constituted by its effects on sentient beings, which themselves have objective value. I am only considering temporal effects (bracketing off any others by my use of the term 'forever'). Whilst an action may have some intrinsic value (i.e. have value not solely due to the value of its later effects), whatever intrinsic value it has is either atemporal or temporally locatable at the time it is performed; and thus, in either case, it cannot be that in virtue of which it non-relatively matters forever (if it does matter forever). If an action is to 
non-relatively matter forever, it can only be because of its further effects. Once its valueaffecting effects finish, its non-relative mattering is finished. And once sentient life is finished, given Welfarism, value-affecting effects are finished.

Given all of the above, we may make the title question of whether or not any action we perform matters forever more precise by disambiguating it.

First, we may consider the relative sense of mattering:- Does any action we perform matter forever in the relative sense? Is there at least one action of ours such that there is forever someone to whom it matters, to whom is important, to whom it has significance? (This needn't be forever the same person - an everlasting series of persons caring in succession about an action of ours would suffice.) And, second, we may consider the non-relative sense:Does any action we perform matter forever in the non-relative sense of mattering? Has it (non-relative) importance or (non-relative) significance forever? And - pushing aside then impersonal value as likely of little (if any) importance and in any case being subject to clear lack-of-longevity concerns - we may say that this question resolves into whether or not there is forever going to be someone for whom some action of ours is important, the value of whose life that action forever affects. (Again, it needn't be forever the same person - an everlasting series of persons for whom it was important that we had performed a particular action would suffice.)

On either reading then, we're in a position to see that the future of mattering is linked to the future of persons. For something to relatively matter at a time, there must be someone to whom it matters at that time; for something to non-relatively matter at a time, there must be someone for whom it matters at that time. And so, it's three broad views on the future of persons to which we'll turn to see what answers the title question (or questions as we've disambiguated it) should receive on them.

\section{II - Three Views of our Ultimate Destiny}

There are innumerable views about our ultimate destiny, but the following taxonomy seems to leave little out. First, there is no everlasting afterlife, for any of us. Second, there are everlasting afterlives for at least some of us, some of which differ in some evaluable ways from those had by others. Third, there are qualitatively undifferentiated (in terms of overall value) everlasting afterlives for all of us. I shall consider the most plausible variants of these three views in order. ${ }^{12}$

1) First then, the no-everlasting-afterlife view. Let's consider relative-mattering first. On the most plausible variants of atheistic naturalism, this universe is all that there is and for each of us there will come a time when nobody cares about anything we've done, as we'll have been long dead and completely forgotten about. Thus, in the relative sense of mattering, nothing we do matters forever. Of course there are some (it seems to me implausible) atheistic naturalistic views whereby that is not all true; perhaps there's a meta-universe beyond ours and some everlasting - but non-divine - super-being is watching us from this vantage point and caring deeply about some (or even all, why not?) of what we do; this super-being is so constituted as to continue to care about it ad infinitum. But I think it safe to ignore such views in what follows. (I also ignore some theistic views which posit no everlasting afterlife perhaps the Sadducees held such a view, though I'm not aware of any extant theistic view on which none of us have everlasting afterlives.) So, painting with a broad brush, on the atheistic naturalistic worldview, for each of us as individuals, whilst at least some of what we do will 
be cared about by us and, no doubt, by some who knew us after our deaths, this caring will trail off with time and, for most of us, after a generation or two, it will disappear entirely. In any case, in the Heat Death of the universe, if not long before, persons as such will cease to exist and therefore then, if not before, caring will cease to exist. Thus then, if not before, the mattering of every one of our actions in the relative sense will cease to exist. So, on the atheistic naturalistic worldview in any of its plausible variants, nothing we do matters forever in the relative sense. What about the non-relative sense?

On this worldview, in its most plausible variants, if anything we do is going to non-relatively matter forever, then it can only be due to its effects in this universe that it non-relatively matters forever. Our intentions and character traits may add value when we act from them, but such value is locatable in time with them and thus ceases at our individual deaths, if not before; there is no other world beyond in which they persist. It is plausible that our effects outlast us in this world by longer than our intentions, character traits, or indeed cares, but by how much longer? Forever? It has seemed plausible to many that a hundred years after our deaths, this world will be, in its evaluable aspects, indistinguishable from how it would have been if we had never lived at all. If one thinks that a hundred years is too small a time span to make such a claim true - after all, surely some figures at least, the Winston Churchills of this world, have evaluable effects that continue centuries after they have died - then one can substitute other timespans - a thousand years; a million, if needs be. Again, we can always refer to the Heat Death if nothing earlier will suffice. Even if it's plausible that the consequences of our actions continue ad infinitum, it's not plausible that they continue to have value-affecting dimensions ad infinitum. It may well be that certain (perhaps all) of our actions have consequences which extend infinitely into the future, but if a welfare-affecting requirement on non-relative mattering is right, then these consequences cannot non-relatively matter after people have ceased to exist and hence then, if not before, the non-relative mattering of all of our actions will cease.

So, in short, the most plausible variants of atheistic naturalism - ones which don't posit transuniversal super-beings caring about our actions or giving us some sort of everlasting afterlife - predict an end to persons and thus an end to relative and non-relative mattering. In practice of course the relative mattering of our actions will have been lost eons before the Heat Death of our universe and it's plausible that the non-relative mattering of our actions will have been lost long before then too. On this worldview, in its most plausible variants, there will come a time at which there are no persons, and, beyond that time, our actions must (given a welfareaffecting requirement) lose non-relative importance even if they've managed to retain some of it prior to then. Thus, on the most plausible variants of the atheistic naturalistic worldview, nothing we do matters forever in any sense. On this worldview, in its most plausible variants, the answer to our title question is a straight 'No'. It isn't necessary on this worldview that it's a 'No', but it is overwhelmingly plausible that it is contingently a 'No'.

2) Now to the second view of our ultimate destiny: there are everlasting afterlives for some of us, some of which differ in some evaluable ways from those which are had by others. One could hold to this view and yet be an atheist - the right sort of trans-universal super-being might teleport us to everlasting afterlives at the moments of our deaths (with a bit of bodyswapping to hide the evidence) and give some of us better afterlives than others, but such views are rightly unpopular. The most popular view associated with thinking that this is our destiny is theism and this is the worldview that I'll focus on. ${ }^{13}$ So then, let us consider the prospects of some of what we do mattering forever on the supposition, held perhaps by the majority of theists, that death means a division between those who go on to an everlasting Heavenly afterlife (even if via Purgatory) and those who do not, the latter being sent to an 
everlasting Hell. This worldview then at least keeps us around and thus - given that for relative-mattering there must be people to whom things matter and for non-relative (given the welfare-affecting requirement) people for whom things matter - it obviously has more resources than the atheistic naturalist worldview we've just been looking at to keep both sorts of mattering around. Given that the afterlife it posits is everlasting, it obviously has more resources to keep both sorts of mattering around forever. ${ }^{14}$ We need not look only to this world to see what effects our actions have and thus observe that after a hundred years - a thousand or million, if you prefer - anyone who might have cared about them will have vanished and all their evaluable effects will have been washed out. We can look to the next world. Then, on the further assumption that which post-mortem fates awaits us depends on certain of our ante-mortem actions, those ante-mortem actions which determine the value of our post-mortem life matter forever. It is worth stressing that this does depend on this further assumption. If one held that there is this division between differing qualities of afterlives, but what fixes who goes where is an action of God's that is independent of anything we might choose - He pre-elects certain people to one fate and others to the other - then one couldn't hold that anything one did mattered forever due to its affecting the value of our afterlives, which value-effect persists forever. But the idea that some actions of ours determine whether we'll everlastingly go to Heaven or everlastingly go to Hell has been popular. And, as well as us, to and for whom some of our actions can potentially matter forever, there's God to consider on this worldview - perhaps some of our actions can matter to and for Him forever too.

I myself do not think that this is a very plausible worldview for a host of reasons, but, on it, it seems to me that the answer to our title question is a straight 'Yes'. Those actions of ours which determine whether we end up ultimately in Heaven or Hell matter forever. First, they matter forever in the relative sense or will do so. ${ }^{15}$ For those of us in Heaven, it'll end up mattering forever to us that we chose rightly; once we get there and realise, perhaps for the first time, which actions of ours ${ }^{16}$ are those on which our everlasting fate turned, we'll deeply care that we performed them and plausibly continue to care deeply ad infinitum. This will be pointless gladness. It's not as if by the time we're in Heaven we have anything to learn from it. But gladness is an intrinsically good thing. One can, after all, relish the pointless gladness of reflecting on the fact that one picked the right horse as one counts one's winnings. For those of us in Hell, things will be - needless to say - somewhat different, but not when it comes to the continuing relative mattering of the actions which have led to our being there. Whether we're in Heaven or Hell, our caring about our having performed the actions which have resulted in our getting there will be pointless - no affective reflection on it can improve our behaviour from then on, and so on. But, just as for those in Heaven the gladness borne of reflecting on having got it right will be intrinsically worth having and thus present, so the intrinsic badness of remorsefully reflecting on having got it wrong will add to the torments of those in Hell and thus that constant remorse will also be present. For those of us in Hell, it will be irrational for us to feel this remorse for the actions which have landed us there; doing so cannot serve any useful purpose; we'd be better off if we stopped 'beating ourselves up' about it; but that's just the sort of pointless suffering that, I take it, is what will make Hell so, well, hellish, for us. ${ }^{17}$

And non-relative mattering? Whether we're in Heaven or Hell, the actions which have led to us being there will matter forever in the non-relative sense; they'll matter forever for us, as they'll be the actions which have had a significant - plausibly the most significant - effect on our wellbeing and that effect will continue forever. 
So, whilst, as I say, I'm not myself sympathetic to this worldview, on it, some of what we do matters forever (or will matter forever) in both the relative and non-relative senses; it'll matter to and for us.

I want to point out though that there's a sense in which such a view just 'kicks the can down the road'. On it, some of what we do ante-mortem - whatever it is the doing of which determines our post-mortem fate - matters (or will matter) forever, in both the relative and non-relative senses. But does anything we do after our salvation or damnation is assured matter forever? So, consider some residents of Heaven (or Hell) addressing our title question as the question of whether or not anything they do now matters forever. Consider first the relative sense. Do they at least care about what they do? As it seems that doing so adds to enjoyment (in Heaven) and suffering (in Hell), so they will. In Heaven, one may be performing the action of worshipping God with a harp and may well care deeply about that. In Hell, one may be vigorously poking another with a trident and care deeply about that, in this case of course - so as to keep Hell as negative as possible - it'll be important to one in the sense that one will passionately wish to stop doing it, but find oneself pathologically continuing nonetheless. Could that day's playing the harp or poking with a trident continue to be cared about the next day? It seems to me that it could be. Past actions can matter to one, as we have seen, and whilst on Earth our capacities to remember, let alone care for, our past actions are limited, it doesn't seem implausible to me to imagine that these limitations will be swept away in Heaven and Hell, for good and ill. If so, then perhaps everything we do in Heaven or Hell will matter to us forevermore; in Heaven, all to the good; in Hell, all to the bad. I would admit though that this is somewhat speculative, depending as it does on the assumption that there is no upper limit to the number of occurrent cares it's metaphysically possible we might be able to entertain post-mortem. ${ }^{18}$ What about the non-relative sense of mattering?

Nothing we can do when we get to Heaven or Hell can affect the quality of our (or anyone else's) afterlives. ${ }^{19}$ That being so, it seems to me we should conclude that nothing we can do in Heaven and Hell can non-relatively matter forever, or indeed at all.

As well as ourselves, there is also God to consider. First, we may consider which of our actions matter to God. It could be argued that, for those of us who have got to Heaven, He too will take pleasure in those actions of ours which have led to us being there; so, if God is temporal, those actions will straightforwardly matter forever to God, just as they'll matter forever to us. By contrast, He'll know that it would be pointless to care about those actions which have led those of us who are in Hell to be there and thus - being rational - He'll not care about those; they won't matter to Him in the way that they matter to those in Hell. Presumably, in order for Hell to be as bad as it could be (and God and Heaven to be as unalloyed in perfection as they must be), it's important that the fate of those in Hell doesn't by then matter to anyone (or indeed for anyone) but those in Hell themselves. Or so it seems to me. But other judgments are available here. Perhaps some of the pleasure of those in Heaven comes from looking down on those in Hell and thus it'll matter to those of us in Heaven (as it will be occasion for such pleasures) that those in Hell made the mistakes that led to them being there. And, depending on what one thinks about divine impassability, one might say that even those actions which have led people to Heaven won't affect God and thus matter to Him. If God is atemporal, then arguably nothing we do matters to Him forever, simply because - as stipulated initially - forever is a temporal notion; if there is no time at which God cares about any of what we do, nothing we do matters forever to Him. ${ }^{20}$ So much for relative mattering. As for non-relative, nothing we can do can non-relatively matter for 
God, as there is no way that anything we can do can affect Him in evaluable ways at all - His necessary perfection secures Him against that.

So, on this worldview, all of us are destined for an end-state where nothing we do matters forever in the non-relative sense. In it some of what we did do - what has secured us our ultimate fates - matters forever in the relative and non-relative sense. And in it at least some of what we continue to do (possibly all of it) matters forever in the relative sense too.

3. The third view I want to consider is the one on which each of us is destined for an everlasting afterlife in Heaven and that Heaven is qualitatively undifferentiated, that is the same for each of us in its value. ${ }^{21}$ On this worldview, the answer to our title question seems to me to be a modified version of the 'Heaven half' of the answer given on the worldview just discussed, the worldview where some go to Heaven and others go to Hell. First then, let us consider the relative sense of mattering.

If what I've said already is right, it could be argued that in Heaven we will care about the good things that we did in our ante-mortem lives, as the gratuitous pleasure such reflection on them will bring us is an intrinsic good; even if our care for the bad we have done can only persist until we reach that state beyond which improvement (or diminishment) is impossible, and thus that will not carry with us into Heaven (we'll have no regrets or remorse then), our care for the good we have done may persist forever. However, given that we will have performed different numbers of good actions ante-mortem, making this move would turn this third view into a version of the second, recapitulating in a minor key interior to Heaven the division in quality of afterlives present on the second view between those in Heaven and those in Hell. In any case, on Universalism, whether the Heaven we all get to is 'qualitatively undifferentiated' or not, we will know that none of our ante-mortem actions are ones in virtue of which we have got to Heaven, so we won't have that sense of 'relief' at having picked the right horse, as it were, in our theological gambling. And, as our heavenly afterlives continue, so, as on the second view, we may care deeply about the activities within them - e.g. harp playing. Thus, in the relative sense of mattering, some - possibly all - of what we do when we get to Heaven will matter forever even if none of what we did ante-mortem will do so. And the non-relative sense?

Again, if what I've just said is right, then none of our actions will matter forever for us in the sense of making a difference to the value of our lives that tracks with us forever. So, on this worldview, nothing we do ante-mortem or post-mortem matters forever in the non-relative sense.

Again, there is God to consider, and again His position is arguably a reflection of ours. If one sits relatively lightly on the property of divine impassability and sees God as temporal, it could certainly be argued that He will take everlasting pointless delight in what limited good we did ante-mortem and in the unalloyed good we do post-mortem. Other views on divine impassibility may mean that one wants to say God's not affected by our actions at all - none of them matter to Him. And, if one holds that God is atemporal, then it could be argued that He will take the atemporal analogue of everlasting pointless delight, not strictly-speaking hold that attitude at any time and thus not hold it forever. Whether God is temporal or atemporal, none of what we do will matter for him in that none of what we do can affect His necessary perfection, for good or ill.

\section{III - Concluding Thoughts}


I have argued for a conclusion that is perhaps unsurprising. On atheistic naturalism (in its most plausible variants), nothing we do matters forever in any sense; on theism, in either of the variants of it I have considered, arguably some of what we do ante-mortem matters forever or will matter forever in the relative sense and, depending on whether one thinks we all go to a qualitatively undifferentiated (in terms of net value) Heaven in the end or that some of us go to Hell (or an inferior Heaven) as a result of some of our actions, some of it matters forever or will matter forever in the non-relative sense too. On either variant of theism, we get to an end-state such that, from that moment on, whilst some of what we then do (perhaps all of what we then do) will matter forever in the relative sense, nothing we then do will matter forever in the non-relative sense. So, on atheistic naturalism and theism (on their most plausible variants) either it is already true or it will become true that nothing we do will affect the value of reality in ways that continue forever. So, finally, I wish to consider whether or not the fact (if atheism is true) or future-fact (if theism is true) that there is already or will come a time at which nothing we do matters forever in the non-relative sense is one which in itself matters, matters to and for us now. Here then I am expanding my considerations beyond what it is for actions of ours to matter forever to what it is for a fact to matter forever, assuming - it will be seen - that the mattering of facts can be modelled on the mattering of actions. First, I want to dismiss a Nagel-inspired line of argument for us being able to answer this question negatively and quickly.

At one stage, Nagel famously writes: "It is often remarked that nothing we do now will matter in a million years. But if that is true, then by the same token, nothing that will be the case in a million years matters now. In particular, it does not matter now that in a million years nothing we do now will matter." 22 As we have seen, it is not implausible, on the atheistic naturalistic worldview anyway, that in the Heat Death of the universe (if not well before) all the actions that any of us do will cease to matter to anyone and for anyone; and that fact - if it is a fact - certainly is cared about by some people. Given that they do care, it matters to these people (now) that this is what will happen in the future, that in the future nothing we are doing now will matter to or for anyone. The same argument - mutatis mutandis - works for theism. That being so, we cannot quickly conclude using a Nagelian line of reasoning that if nothing we do matters in a million years (in either sense), then that doesn't matter now (in either sense). It might matter now that in a million years nothing we do now matters - it might relatively matter (we might care about it; indeed some just do care about it); it might even matter non-relatively; it might be bad for us (or good) now that none of our actions matter then.

It seems to me that the attraction of a Nagel-inspired view comes from a principle that is right (albeit that its antecedent is false):- If it is true that nothing matters (tout court), then it is true that it doesn't matter that nothing matters. But that is not relevant to our concerns. Relevant to our concerns is the fact that on atheistic naturalism (in its most plausible variants), it is true that nothing we do now matters (relatively or non-relatively) in a million years. Also relevant to our concerns is the fact that on theism in either of the two variants we've considered, it is true that nothing we do in our end-state non-relatively matters. And my point is that if those claims are true and if one of those worldviews is true, then it might also be true that it matters now (relatively and non-relatively) that nothing we do matters (relatively and/or nonrelatively) in a million years or that it matters now that we're heading for an end-state where nothing we do matters non-relatively.

So, in short, there isn't an easy Nagelian route to a negative answer to the question about whether or not it matters to or for us now that we're already in a state or will end up in a state where nothing we do non-relatively matters forever. Indeed, as we've seen, there is an easy 
route to a positive answer to the question on its relative construal: given that some people just do as a matter of fact care about this present/future fact's obtaining, it obviously just does at least relatively matter now to them. Given that there is this easy answer to the question when mattering now is taken to be relative mattering now, let's focus on the non-relative sense of mattering: does it non-relatively matter now that nothing we do will non-relatively matter in a million years (as is true on the most plausible variants of atheistic naturalism) or that we are now heading for an end-state where nothing we do will non-relatively matter (as on the variants of theism we have considered)? On Welfarism, this then is the issue of whether or not it's good or bad for us now that nothing we do will, in a million years, be good or bad for anyone or good or bad for us now that we will end up in such a state. There is arguably an easy route to a positive answer to this question too given the fact that some people just do care about it and that (as I discussed in footnote 6) an individual's harmless desires being satisfied does in itself affect their welfare positively, albeit to a relatively small extent, and thus it does matter for them. But is there a non-easy route to a more substantial positive (or negative) answer? Do we have reason to care about this, one way or the other? I confess I don't have confidence in how we should answer this question. I have cogent intuitions, but they (a) are weak; (b) are somewhat conflicting; and (c) seem, to my best attempts at candid introspection, rather too closely linked to my personal temperament to be reliable guides as to what is or would be desirable, rather than at best reliable guides simply as to what is, as a matter of fact, desired by me. Without much confidence then, I venture the following by way of concluding thoughts.

Let's consider the atheistic naturalist worldview first. On this view, it seems to me one should conclude that it doesn't non-relatively matter much, if at all, that nothing we do nonrelatively matters forever. The other things in this life that non-relatively matter to and for one and to and for others can matter just as much without anything we do mattering forever in the non-relative sense. So, 'eat, drink, and be merry' is the order of the day. Even if his argument for it isn't sound, a Nagelian conclusion is broadly right. ${ }^{23}$

Turning to consider the theistic worldview, it seems clear to me that it will non-relatively matter to us when we get there that in Heaven (or Hell) nothing we do matters forever in the non-relative sense. On the first - Heaven and Hell - variant of theism, it's going to be good for those of us in Heaven and bad for those of us in Hell, the good or bad of being in an everlasting and unalterably good or bad state. On the second - qualitatively undifferentiated Heaven-only - variant of theism, it's just the first half of this that obtains; it's going to be good for us that nothing we do in Heaven non-relatively matters; it will give us relief; the responsibility for the value of reality will be finally and completely lifted out of our hands. But that's how non-relatively good (or bad) the fact we're reflecting on will be for us then; we are asking about how non-relatively good (or bad) it is for us now that this fact will obtain then. On the Heaven-and-Hell variant (or indeed the qualitatively differentiated Heaven variant), whereby which of these fates awaits us depends on actions that we've yet to perform (and can turn on actions we perform right up to last-moment death-bed conversions), it seems to me it does plausibly non-relatively matter now that we're heading for this state; the inalterability and inescapability (once we're there) of our fates makes all the more nonrelatively important now those actions which lead us to those fates. On the qualitativelyundifferentiated Heaven-only variant, it seems to me that the metaphysical promise, as it were, of a state that will be good for us, isn't in itself good (or bad) for us yet; it doesn't nonrelatively matter for us yet; it doesn't non-relatively matter for us now that we're heading for an end-state in which nothing we do will non-relatively matter forever. ${ }^{24}$ 
It may be quite distinctively human to desire that at least some of our actions matter forever in the non-relative sense, affect the value of reality everlastingly. But we've seen enough to know that it's going to be hard for reality to live up to that desire, very hard for it to live up to that desire forever. One may hope then, and - it seems to me (though I haven't really argued for it) - reasonably believe, that such a desire is not responsive to desirability. ${ }^{25}$ If, of the three worldviews that I've talked about, the one that I personally hope is true is in fact true (the qualitatively undifferentiated Heaven-only variant of theism), then there'll come a day on which we fully realise that this desire to make everlasting differences to the value of reality is not responsive to desirability. That knowledge will be joined with the full realisation of another fact, viz. that we were never in a position to make an everlasting difference anyway. And what we fully realise then will matter to and for us, then and forever after; it'll become a part of what we will forever thank God for. ${ }^{26} 27$

\section{References}

DAVISON, SCOTT (2012), On the Intrinsic Value of Everything (London: Bloomsbury)

KAHANE, GUY (2014), 'Our Cosmic Insignificance’, Noûs, 48 (4), 745-772.

KAHANE, GUY (2017), 'If Nothing Matters’, Noûs 51 (2), 327-353.

KRAAY, KLAAS (2018), (ed.) Does God Matter? (New York: Routledge).

MAWSON, T. J. (2016), God and the Meanings of Life (London: Bloomsbury).

MAWSON, T. J. (2018), The Divine Attributes (Cambridge: CUP).

NAGEL, THOMAS (1971) 'The Absurd', The Journal of Philosophy, vol. 68, no. 20,.716-727.

O'BRIEN, WENDELL, 'Meaning and Mattering', The Southern Journal of Philosophy, 34 (3), 339-360.

WILLIAMS, BERNARD (1986), Ethics and the Limits of Philosophy (Cambridge: CUP).

WILliAMS, BERNARD (2006), in A. Moore (ed.), 'The Human Prejudice', Philosophy as a Humanistic Discipline (Princeton: Princeton University Press)

\section{Notes}

${ }^{1}$ To underscore an important point before I go any further:- In order to focus down on a manageable question, I shall consider solely actions of ours. Even without any of our actions mattering forever, there may well be facts about us which obtain without their doing so being the result of any of our actions at all and some of these might matter forever. If there's a God, there may well be actions of His that matter forever. I do not address any of these issues, except at the very end of the paper.

${ }^{2}$ In what follows then I am taking mattering, having importance, and having significance as synonyms. Though I think my usage is sensitive to a strand of ordinary usage, I would concede that it is somewhat stipulative. Kahane gives a different reading of importance and significance, G. Kahane (2014), My diagnosis is not that I am right and Kahane wrong, just that 'importance', 'significance', and the like are somewhat ambiguous terms.

${ }^{3}$ Williams (1986), 182-183

${ }^{4}$ O’Brien (1996), 342, would disagree. But nothing of substance in my main argument depends on my usage in this particular - it just makes things simpler by meaning I don't need to include mention of the threshold at various stages or worry about vagueness (for it's plausible that the threshold is a vague one).

${ }^{5}$ I owe this point to O’Brien, op. cit.

${ }^{6}$ In fact, given that I shall later endorse a view of what it is to matter in this non-relative sense whereby it is to affect the value of a person's (or sentient being's) life (I call this 'Welfarism', though this term is not itself ideal either; it shouldn't be seen as committing one to Utilitarianism, for example) and given that I think that satisfying in-themselves-harmless desires such as Henry's does do something, even if not much, to improve Henry's life, so it does matter a little bit for Henry in this non-relative sense that he is able to buy the missing stamp. Reality - his bit of it - is made somewhat better by his finishing his stamp collection than it would otherwise have been, but just - I am assuming - not much better, not much better especially in comparison to how much better it is being made by his continued charitable giving. 
${ }^{7}$ There is a dispositional property that one might talk about here too; I bracket it off with is move in the main text primarily to keep things simple; what I have to say later could be adapted to cater for the dispositional property.

${ }^{8}$ According to Kahane, the terminology is not ideal for other reasons too. See Kahane (2017). I do not agree with all his other reasons, but cannot open up too many lines of argument in this paper.

${ }^{9}$ B. Williams (A. Moore (ed.)) (2006).

${ }^{10}$ Remember I am taking caring as an occurrent attitude, as more than just a disposition towards that attitude. On my account, for us to care about the alien's action requires more than that it be true of us that we would care about it were we to become aware of him and his choice. The situation here is more complicated on the dispositional account of caring, admittedly. Had I not bracketed that off somewhat stipulatively earlier to keep things simple, then, in order to make my point with this example, I would need to add that the alien has already hypnotized us so that we are such that, were we to become aware of him and his choice, we would not in fact care about it.

${ }^{11}$ Others would disagree, e.g. Scott Davison (2012).

${ }^{12}$ I am ignoring Annihilationism in what follows, for simplicity; I hope it can easily be seen how what I say in the main text could be adapted for this view.

${ }^{13}$ Hinduism and Buddhism deserve mention here. Of course both of these religions (families of religion) are so broad that generalising is fraught with difficulty. But we may talk of those religions which posit reincarnation as positing an afterlife (whether or not they see something like a theistic God or an impersonal karma behind it), but if they posit that everyone of us eventually - even if only after many millennia - escapes from the cycle of rebirth, then these accounts don't posit an everlasting afterlife for any of us. They may thus be treated for the purposes of the argument of this paper as variants of the first view discussed in the main text. A wrinkle may come if they posit that, with the last person escaping from rebirth, time as such will cease to exist, in which case they have more resources to maintain that persons (things to and for whom in principle actions can matter) exist forever and thus mattering may well exist forever. Things are similar if they posit everlasting gods who care about us or are affected by us. Of course their view on the ontological status of persons may not support some of the more basic claims of this paper.

${ }^{14}$ Variants which posit only non-everlasting afterlives revert in substance to the no-everlasting-afterlife view just discussed. Similarly, a view which may be lumped in with the first for the purposes of this argument is the theistic one where we have 'afterlives', but these are atemporal - the only temporal medium in which we ever live is that of this universe. Then our situation 'after' death will mirror that of the atemporal God discussed in the main text later.

${ }^{15}$ There is a technicality here which I rather slide over in the main text. In the time between our performing the relevant actions and the effects coming about, the actions may not matter to (or indeed for) us; so, technically they will not matter forever in the sense defined; there won't be no time at all after we've performed them at which they don't matter, though God might fill the gap with respect to relative mattering, with some of His ongoing cares. And the dispositional account of caring could also be reintroduced at this stage to some effect.

${ }^{16}$ And also which actions of others (for our fates seem plausibly affected by those too). For simplicity, I won't consider this epicycle to the account in the main text.

${ }^{17}$ One might say of such pointless sadness that it is nevertheless 'appropriate' or 'fitting' and that - even though instrumentally valueless and intrinsically worth avoiding due to its 'hedonic tone', as it were - its appropriateness to the situation alone gives it at least some value. By some I will thus be seen to downplay such 'fittingness-of-attitudes' values, acting as I am on the assumption that, if they exist at all, they are of negligible non-relative importance (unless they are instrumentally valuable). If the fittingness of such attitudes and cares has greater intrinsic value than I am inclined to attribute to it, then that will affect the distribution of such attitudes in Heaven and Hell relative to the manner in which I sketch it in this section. Nothing more major than that will be affected in my argument.

${ }^{18}$ Though the need for this assumption is an artefact of my taking caring as an occurrent mental state, which view, it will be recalled, I adopted solely to keep the exposition simpler.

${ }^{19}$ This is assuming they are what I am calling 'qualitatively undifferentiated' from each other.

${ }^{20}$ Though see T. J. Mawson (2018) for how an atemporal God may nevertheless be said to exist at (all) times.

${ }^{21}$ I assume in what follows that if the most plausible variant of this view (which I take to be theistic universalism) is true, it will be known to be true by all of us in our post-mortem end-state; ignorance of its truth would, I take it, detract from the perfection of the Heaven to which, by then, we shall all have been transported. ${ }^{22}$ Nagel (1971), 716.

${ }^{23}$ I haven’t really argued for this here; for argument to this effect see Mawson (2016), 146ff.

${ }^{24}$ Or so it (tentatively) seems to me. But Nick Waghorn, for one, would call it differently. He writes in personal correspondence, that (on various assumptions) 'the fact that nothing we do non-relatively matters forever seems to be grounded, on atheism, in a further fact, namely: 'That the universe is incapable of supporting non-relative- 
value-grounding sentient life forever'. If, as you suggest, the mattering of facts can indeed be modelled on the mattering of actions then since this fact is true now (and at all times) on atheistic naturalism, it affects persons now, and so non-relatively matters for persons now.'

${ }^{25}$ There are obvious connections here to issues in the Pro-theism/Anti-theism debate. See K. Kraay (ed.) (2018).

${ }^{26}$ Waghorn writes in personal correspondence that 'we might ask why we want our actions to non-relatively matter forever. The only stories that look convincing to me are those that appeal to the fact that such actions would cause some sort of good to accrue to us in some way forevermore, and we want that to happen...But if we know that at some future point in time good will accrue to us maximally, and for infinite future time, regardless of our actions, the need for our present actions to non-relatively matter forever seems much less pressing; all we really need are actions that non-relatively matter for all time up until the aforementioned point. So provided that the reason for why our actions do not non-relatively matter forever is of the right sort (that we are guaranteed a Heavenly afterlife, rather than that all sentient life will ultimately die out), it does not seem to non-relatively matter that our current action will not non-relatively matter forever.'

${ }^{27}$ I am grateful for comments on this paper made by those meeting under the aegis of the Athenaeum's Natural Theology Group: Claire Carlisle, John Cottingham, Douglas Hedley, Dave Leal, and James Orr. I am also grateful to Wendell O’Brien, Stewart Goetz, Guy Kahane, Klaas Kraay, John Schellenberg, and Nick Waghorn, who were kind enough to offer comments on the paper. I am also very grateful for the comments of an anonymous referee for this journal. 